American Medical Journal 2 (2): 119-124, 2011

ISSN 1949-0070

(C) 2011 Science Publications

\title{
The Effect of Antioxidants Supplement on Lipid Peroxidation and Serum Aryl Esterase Enzyme in Rheumatoid Arthritis Patients
}

\author{
${ }^{1}$ Mahsa Jalili, ${ }^{2}$ Seyed-Rafi Aref-Hosseini, ${ }^{3}$ Sousan Kolahi, \\ ${ }^{4}$ Mehrangiz Ebrahimi-Mamegani and ${ }^{5}$ Siamak Sabour \\ ${ }^{1}$ Nutrition Faculty of Shahid Beheshti University of Medical Sciences, \\ ${ }^{2}$ Department of Food Sciences, Faculty of Health and Nutrition, \\ ${ }^{3}$ Department of Internal Medicine, Emam Reza Teaching Hospital Health, \\ ${ }^{4}$ Department of Nutrition and Diet Therapy, Faculty of Health and Nutrition, \\ ${ }^{5}$ Department of Statistics and Epidemiology, Faculty of Health and Nutrition, \\ Tabriz University of Medical Sciences, Iran
}

\begin{abstract}
Problem statement: Rheumatoid Arthritis (RA) is one of the common autoimmune diseases with unknown etiology that its prevalence ratio in females to males is 3:1. It has been suggested that serum antioxidant levels is reduced and lipid peroxidation is increased due to oxidative stress. According to a recent research, antioxidant supplements may play an important role in controlling oxidative stress. The aim of this study is to investigate the effect of antioxidants supplement on serum Aryl Esterase Enzyme (ARE) and serum Malondialdehyde (MDA) in RA patients. Approach: A prepost study was conducted in a 3 month period on 40 female RA patients which receiving daily one SelenPlus capsule (selenium $50 \mathrm{mcg}$, zinc $8 \mathrm{mg}$, vitamin A $400 \mathrm{mcg}$, vitamin C $125 \mathrm{mg}$ and vitamin E $40 \mathrm{mg}$ ). About $5 \mathrm{~mL}$ venous blood sample was taken from all participants and serum levels of ARE and MDA were measured spectrophotometerically. Distribution of the variables were assessed using histogram with normal curve as well as Kolmogrov-Smirnov test and Data were analyzed with paired t test for differences between pre-post data using SPSS software version 13.5. Results: Out of 40 patients, 39 completed the study. In comparison with the baseline, we found significant differences between serum aryl esterase and malondialdehyde values before and after intervention. The 3-month supplementation resulted in increasing ARE activity $(p<0.001)$ and reduction of MDA levels $(p<0.001)$. Conclusion: The antioxidantssupplement for 3 months resulted in significant improvement in ARE activity and reduction of lipid peroxidation marker and may be helpful in RA treatment.
\end{abstract}

Key words: Rheumatoid arthritis, antioxidant supplement, oxidative stress, aryl esterase, malondialdehyde

\section{INTRODUCTION}

Rheumatoid Arthritis (RA) is one of the most common autoimmune diseases with unknown etiology (Gill and Feinstein, 1994; Mikuls, 2003; Wang et al., $2008)$ and its prevalence in adults is $1 \%(0.4-2.1 \%)$ in the world and almost three folds more women than men are affected (Westaway et al., 2008). In Iran, the incidence of RA in one million people is approximately 750 cases and they were 600000 people in 1995. The main characteristics of Rheumatoid arthritis are swelling, pain and physical movement impairment that eventually cause joint deformities and osteoporosis.
The RA has direct connection with other chronic diseases like cardiovascular diseases that are the most important problems of public health in community (Goldberg and Katz, 2007; Yang et al., 2010). Several studies have shown that oxidative stress play a role in causing of RA development and epidemiologic studies have been reported inverse relationship between intake of dietary antioxidants with the incidence of RA (Karatas et al., 2003; Pattison and Winyard, 2008). With the reduction of dietary intake of antioxidants, the amount of antioxidant enzymes including serum aryl esterase are reduced (Isik et al., 2007; Rennie et al., 2003); On the other hand, due to the interaction of

Corresponding Author: Sousan Kolahi, Department of Internal Medicine, Emam Reza Teaching Hospital Health, Tabriz University of Medical Sciences, Iran 
medications with nutrients, disability in movement and long-term gastrointestinal complications; malnutrition is common in RA patients, so dietary antioxidants intake has been reduced (Pattison et al., 2004a; Stamp et al., 2005; Martin, 1998). Antioxidant supplements such as vitamin E (Edmonds et al., 1997; Helmy et al., 2001), vitamin C (Pattison et al., 2004b) and selenium (Pretez et al., 2001; Tarp et al., 1985) can prevent or delay lipid peroxidation and reduce oxidation indices in RA to prevent or delay it (Kamanli et al., 2004; Venkatraman and Chu, 1999). Because the components of antioxidant defense system works integrated and lack of one antioxidant affect on other antioxidants activity and lead to oxidative stress (Evans and Halliwell, 2001), so combination of antioxidants can reduce peroxidation and improve serum antioxidant indices which may be useful for RA patients.

The aim of this study is to determine the effect of combined antioxidant supplementation of "SelenPlus" on the level of serum malondialdehyde and serum aryl esterase enzyme in women 40-60 years old which suffering from rheumatoid arthritis.

\section{MATERIALS AND METHODS}

Study design and patients: Four hundred RA patients recorded in the Center of Sheikh Al raees and Sina Clinic of the Tabriz University of Medical Sciences and 40-60 years old women with RA based on proven inclusion criteria included in the study.

Recognition of RA confirmed by rheumatologist according to American College of Rheumatology (ACR) criteria (including (1) morning stiffness for at least an hour, (2) stiffness for more than three joint, (3) arthritis of hand joints, (4) symmetrical arthritis, (5) rheumatoid nodules, (6) positive rheumatoid factor, (7) typical clinical radiographic changes in the wrist and hand) and patients have not changed their treatment protocol, for at least 2 months. The exclusion criteria include having diabetes mellitus, hypertension, thyroid disorders, renal failure, liver dysfunction, Cushing's syndrome, as well as smoking and being exposed to smoke at home daily; any changes in treatment protocol and drug therapy for any reason that led to omit from the study. The study was pre-post test and the intervention period was 3 months. The patients were asked to take daily "SelenPlus" capsule (Euro vital Pharmaceutical Company, Germany) that containing Selenium $50 \mathrm{mcg}$, zinc $8 \mathrm{mg}$, Vitamin A $400 \mathrm{mcg}$, Vitamin C $125 \mathrm{mg}$ and vitamin E $40 \mathrm{mg}$. The containers of capsules did not have any commercial logo. Before entering the study, detailed clinical examination was performed by Rheumatologist and filled up the forms of personal data, medications, food intake for 3 days ( 2 working days and a regular holiday) and food frequency questionnaire by a trained nutritionist andanalyzed the energy intake, macronutrients and antioxidant micronutrients by Nutritionist III software (MAM research soft co, USA). Also, anthropometric indices including weight, height were Measured and Body Mass Index (BMI) was calculated, weight was measured by calibrated digital scale for each individual with minimal clothing and without shoes and height was determined by stadiometer according to contact of 4 points of the body (back of the heel, hip, shoulder and head) with wall by controlling the stadiometer precision for each measurement. body mass index was calculated using the Quetelet's index:

$$
\mathrm{BMI}=\frac{\mathrm{Wt}(\mathrm{Kg})}{\mathrm{Ht}^{2}(\mathrm{~m})}
$$

Five $\mathrm{ml}$ fasting venous blood samples (8-12 $\mathrm{h}$ after fasting) were taken from all participants and after that, were stayed in room temperature (half hour later) to separate serum samples. All samples were centrifuged by Hettich Universal (D-7200, Germany) with speed of 2000 rpm for 20-15 min. Until conducting biochemical measurements, samples were placed in the $-70^{\circ} \mathrm{C}$ freezer (Snider's, Germany). To follow up the taking of supplements ongoing call was taken every 2 weeks. After 3 months of intervention, filling up the forms, blood sampling and measurements were repeated.

Biochemical measurements: Serum malondialdehyde levels as the marker of lipid peroxidation were determined by Thiobarbitoric acid reaction with acid that was extracted with n-Butanol and measured spectrophotometerically at $523 \mathrm{~nm}$ wavelength and compared with standard curve (Sarban et al., 2005; Taysi et al., 2002). Serum aryl esterase activity was assessed by reaction with phenylacetate method, measured spectrophotometerically at $270 \mathrm{~nm}$ wavelength on the temperature of $25^{\circ} \mathrm{C}$.

Sample size calculation: Sample size was determined according to similar studies (Tarp et al., 1985) and available facilities as follows:

$$
\begin{gathered}
\mathrm{SD}=2.7 \Delta=2.2 \\
\mathrm{~N}=\left[2(\mathrm{SD})^{2}\left(\mathrm{Z}_{\alpha / 2}+\mathrm{Z}_{\beta}\right)^{2}\right] / \Delta^{2} \quad \mathrm{~N}=23.6
\end{gathered}
$$

According to long duration of intervention and high probability of lost to follow up, 40 patients were selected. 
Am. Med. J. 2 (2): 119-124, 2011

Statistical analysis: SPSS statistical software version 13 (SPSS for windows, Chicago, IL, USA) was used for statistical analysis. To test normal distribution of data Q-Q plot and Kolmogrov-Smirnov test were used. For testing the mean differences of before-after data, paired t-test was used for normal data and in case of nonnormal; wilcoxon-rank test was used. In order to adjust for confounding factors, linear regression model was used. All of the tests were done two-sided and p.value $<0.05$ were defined significant. Qualitative Data were expressed as median (minimum, maximum).

Ethical issues: After calling and explaining the method of performing the intervention for each patient, written informed consent form was collected from all participants. Registration code of the local ethics committee of Tabriz University of Medical Sciences is the number 8912 and registration number in the registration center for clinical trials in Iran, is IRCT138901183655N1. In case of any side effects, patients could leave the study and prescribed dose of each antioxidant nutrient was kept at the Recommended Dietary Allowances (RDA) level.

\section{RESULTS}

Out of 40 patients, 39 completed the study. One person was deleted from the study due to unrelated medical problem (Fig. 1).

Table 1 shows demographic, anthropometric and pharmacologic characteristics of the participants at the beginning of the study (Table 1). Dietary intake of energy, macronutrients and antioxidant micronutrients during the 3 months of intervention did not change significantly (Table 2) and in the linear regression model, no significant relationship between dietary antioxidants intake with biochemical indices was present.

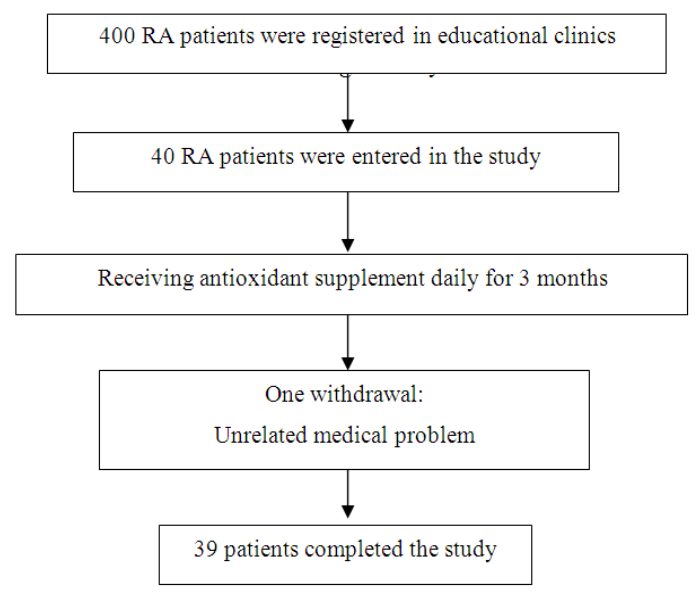

Fig. 1: The patients participated in the study

Table 1: Demographical, anthropometric and pharmacologic characteristics of female RA patients in the baseline of the study

\section{Variables}

Gender (number)

Age (yrs)*

Weight $(\mathrm{kg})^{*}$

Height $(\mathrm{cm})^{*}$

BMI $\left(\mathrm{kg} / \mathrm{m}^{2}\right)$

Disease duration (months) $\ddagger$

Prednisolone use $\dagger$

Methotrexate use $\dagger$

Sulfasalazine use

Cloroquine use $\uparrow$

Cyclosporine use $\dagger$

NSAIDs use

Imuran use $\dagger$

Other drugs use

*: mean \pm SD: $\$$ median (min, max): $\dagger$ number (percent)

Table 2: Dietary intake of energy, macronutrients and antioxidant micronutrients in female RA patients in the study before and after 3 months

\begin{tabular}{lccc}
\hline & Before the study & After the study & \\
Variables* & $\mathrm{n}=40$ & $\mathrm{n}=39$ & $\mathrm{p}$-value $\neq$ \\
\hline Energy (kcal) & $1534.5(701,5253)$ & $1603.0(797,3741)$ & 0.59 \\
Protein (gr) & $48.3(15,123)$ & $43.3(16.8,122)$ & 0.45 \\
Carbohydrate (gr) & $195.0(84.9,535)$ & $183.0(76.6,563)$ & 0.95 \\
Fat (gr) & $75.8(21.7,149)$ & $73.5(17.8,363)$ & 0.83 \\
Zinc (mg) & $5.2(1.7,13)$ & $5.1(0.3,14.5)$ & 0.76 \\
Vitamin A (IU) & $4699.5(133,35312)$ & $3998.0(239,33375)$ & 0.49 \\
Vitamin E (mg) & $32.1(2.9,83.7)$ & $32.5(2.8,317.0)$ & 0.44 \\
Vitamin C (mg) & $102(15.1,446)$ & $94.0(18.4,361.0)$ & 0.79 \\
\hline
\end{tabular}

*: Median (min, max); $\neq$ : Wilcoxon rank test

Table 3: Serum malondialdehyde levels, aryl esterase activity and HDL$\mathrm{c}$ in female RA patients in the study before and after 3 months

Variables $\quad$ Before the study After the study

\begin{tabular}{llll} 
& $\mathrm{n}=40$ & $\mathrm{n}=39$ & $\mathrm{p}$-value $\$$ \\
\hline${\text { Serum } \mathrm{MDA}^{1}(\mathrm{nmol} / \mathrm{mL})}^{3.31 \pm 0.70}$ & $2.82 \pm 0.76$ & $<0.001 \dagger$
\end{tabular}

$\begin{array}{llll}\text { Serum } \mathrm{ARE}^{2}(\mathrm{U} / \mathrm{L}) & 76.01 \pm 37.08 & 103.76 \pm 58.00 & <0.001 \dagger\end{array}$

$\begin{array}{lrl}\text { Serum HDL }-\mathrm{c}^{3}(\mathrm{mg} / \mathrm{dL}) & 51.70 \pm 12.70 & 51.70 \pm 11.60 \quad=0.79 \ddagger\end{array}$

Mean \pm SD; $\uparrow$ : There was significant difference between before and after values $(\mathrm{p}<0.001)$; $\$$ : There was no significant difference between before and after values: $§$ Paired t-test: (1) Malondialdehyde:

(2) Aryl esterase: (3) High-density lipoprotein cholesterol

Three months after supplementation with combined antioxidants, serum levels of malondialdehyde and aryl esterase activity changed statistically significant (p.value $<0.001$, p. value $<0.001$ respectively) (Table 3).

\section{DISCUSSION}

In our trial, antioxidant supplementation for three months could significantly reduce serum levels of malondialdehyde $(\mathrm{p}<0.001)$. The similar results were obtained by Shinde et al. (2010) that indicated the effect of antioxidant vitamin supplements (vitamin E $400 \mathrm{mg}$ and vitamin C $500 \mathrm{mg}$ per day) on significant reduction in serum levels of malondialdehyde $(\mathrm{p}<0.05)$. Also, Jaswal et al. (2003) reprted positive effect of 
combined antioxidants supplementation (vitamin E, A and $\mathrm{C}$ with no mention of the dosage) on the reducing of lipid peroxidation levels compared to control group after 3 months supplementation in RA patients.

Nourmohammadi et al. (2010) studied the antioxidant supplementation with vitamin C $300 \mathrm{mg}$, zinc 5mg and vitamin A 25000 International Unit (IU) as every other day for 12 weeks that reduced the level of lipid peroxidation. We used serum levels of malondialdehyde as a marker of lipid peroxidation and previous studies indicated the increased lipid peroxidation in patients with RA (Pattison et al., 2004b) and the lack of certain nutrients, such as antioxidants on different areas of Iran has been reported previously (Hakimi et al., 2006). According to WHO report in 2009 , there is marginal deficiency of vitamin A in most parts of Iran (WHO, 2009) and serum levels of antioxidants in patients with RA are lower than healthy people (Bae et al., 2003), so supplementation with combination of the antioxidants may be useful to reduce lipid peroxidation.

In contrast with our study, Jacob et al. (2003) showed that supplementation with antioxidants (vitamin C $272 \mathrm{mg}$, alpha-Tocopherol $31 \mathrm{mg}$ ) for 3 months in healthy men did not have beneficial effects on the level of serum malondialdehyde compared with control group. This study was conducted with low doses of antioxidants (Jacob et al., 2003) and the combination of antioxidants (Vitamin C $250 \mathrm{mg}$, beta-carotene $3 \mathrm{mg}$ and D-alpha-Tocopherol $67.1 \mathrm{mg}$ with $5 \mathrm{mg}$ zinc and catechinpolymer of grape seed extract $3.89 \mathrm{mg}$ and milk thistle extract $8.4 \mathrm{mg}$ ) failed to reduce significantly the level of malondialdehyde in serum samples (Peng et al., 2000).

Meanwhile, our study revealed that serum aryl esterase activity was increased significant after 3 months of intervention with antioxidant supplements (p.value <0.001).

Circulating aryl esterase enzyme (EC 3.1.8.1) is a cysteine esterase that has homologous structure with serine esterases. There is a serine group in its active position which has the same catalytic mechanism of Paraoxonase Enzyme (PON) (Sorenson et al., 1995). Significant reduction of serum aryl esterase has been reported in inflammatory diseases such as RA (Baskol et al., 2005) and serum levels of ARE can be considered as a marker of oxidative stress (Koksal and Kurban, 2010); also, ARE levels is in relation to serum lipid levels, especially serum HDL (Adkins et al., 1993); thus increasing serum levels of ARE as a marker of lipoprotein fraction of serum antioxidants may indicate antioxidant defense system and improvement of cardiovascular health in RA patients (Don et al., 1975).
To the best of our knowledge, aryl esterase has not been studied as an antioxidant marker for antioxidant supplementation trials in RA patients.

Reactive Oxygen Species (ROS) are very active and have the ability to react with intracellular components and cause damage to surrounding tissues; they increase other free oxygen radicals and increase oxidative stress and risk of chronic diseases (Elkiran et al., 2007). The level of ARE enzyme inversely related with serum levels of oxidative stress components in serum and macrophages and reduced activity of ARE is a marker of high levels of oxidative stress (Rozenberg et al., 2003), so it seems that increased serum ARE after 3 months of antioxidant supplementation may indicate the reduction of the level of oxidative stress indices and improving antioxidant defense in patients with RA. One of the weaknesses of our study is lacking the control group. The strengths of the study are the high response rate $(97.5 \%)$ as well as not losing power due to lost to follow up over 3 months. Also, we considered the mild to moderate severity of RA disease activity as a criterion for entering the study and the dietary intake of antioxidants as confounding factors.

\section{CONCLUSION}

Overall, the results of our study confirmed the effect of oxidative stress in RA disease and showed that antioxidant supplementation may play important role in reduction of lipid peroxidation and increasing of the antioxidants levels in the antioxidant defense system.

\section{ACKNOWLEDGMENT}

This study was granted by Research Council of Health and Nutrition Faculty of Tabriz University of Medical Sciences, Iran and the Research Team of Rheumatology in Tabriz University of Medical Sciences. Also, we thank Pharmaceutical Research Center of Tabriz University of Medical Sciences, due to cooperation in biochemical assessments. We would like to thank all staffs of Sina and Sheikh al raees clinics. It is necessary to appreciate all the patients who participated in this study and all those helped us in the implementation of this research.

\section{REFERENCES}

Adkins, S., K.N. Gan, M. Mody and B.N.L. Du, 1993. Molecular basis for the polymorphic forms of human serum paraoxonase/arylesterase: glutamine or arginine at position 191, for the respective A or B allozymes. Am. J. Hum. Genet., 52: 598-608. 
Bae, S.C., S.J. Kim and M.K. Sung, 2003. Inadequate antioxidant nutrient intake and altered plasma antioxidant status of rheumatoid arthritis patients. J. Am. Coll. Nutr., 22: 311-315. PMID: 12897046

Baskol, G., H. Demir, M. Baskol, E. Kilic and F. Ates et al., 2005. Assessment of paraoxonase 1 activity and malondialdehyde levels in patients with rheumatoid arthritis. Clin. Biochem., 38: 951-955. PMID: 16055108

Don, M.M., C.J. Masters and D.J. Winzor, 1975. Further evidence for the concept of bovine plasma arylesterase as a lipoprotein. Biochem. J., 15: 625-630.

Edmonds, S.E., P.G. Winyard, R. Guo, B. Kidd and P. Merry et al., 1997. Putative analgesic activity of repeated oral doses of vitamin $\mathrm{E}$ in the treatment of rheumatoid arthritis. Results of a prospective placebo controlled double blind trial. Ann. Rheum Dis., 56: 649-655. DOI: 10.1136/ard.56.11.649

Elkiran, E.T., N. Mar, B. Aygen, F. Gursu and A. Karaoglu et al., 2007. Serum paraoxonase and arylesterase activities in patients with lung cancer in a Turkish population. BMC Cancer, 7: 48-48. DOI: $10.1186 / 1471-2407-7-48$

Evans, P. and B. Halliwell, 2001. Micronutrients: Oxidant/antioxidant status. Br. J. Nutr., 85: 67-74. PMID: 11509092

Gill, T.M. and A.R. Feinstein, 1994. A critical appraisal of the quality of quality-of-life measurements. JAMA., 272: 619-626. PMID: 7726894

Goldberg, R.J. and J. Katz, 2007. A meta-analysis of the analgesic effects of omega-3 polyunsaturated fatty acid supplementation for inflammatory joint pain. Pain, 129: 210-223. PMID: 17335973

Hakimi, S.M., F. Hashemi, N. Valaeei, S.M. Kimiagar and A.A. Velayati et al., 2006. The effect of supplemental zinc on the height and weight percentiles of children. Arch. Iran. Med., 9: 148-152. PMID: 16649358

Helmy, M., M. Shahayeb, M.H. Helmy and E.A. ElBassiouni, 2001. Antioxidants as adjuvant therapy in rheumatoid disease. A preliminary study. Arzneimittelforschung, 51: 293-298. PMID: 11367869

Isik, A., S.S. Koca, B. Ustandag, H. Celik and A. Yildirim, 2007. Paraoxonase and arylesterase levels in rheumatoid arthritis. Clin. Rheumatol., 26: 342-348. PMID: 16642406

Jacob, R.A., G.M. Aiello, C.B. Stephensen, J.B. Blumberg and P.E. Milbury et al., 2003. Moderate antioxidant supplementation has no effect on biomarkers of oxidant damage in healthy men with low fruit and vegetable intakes. J. Nutr., 133: $740-743$
Jaswal, S., H.C. Mehta, A.K. Sood and J. Kaur, 2003. Antioxidant status in rheumatoid arthritis and role of antioxidant therapy. Clin. Chim. Acta, 338: 123129. PMID: 14637276

Kamanli, A., M. Naziroglu, N. Aydilek and C. Hacievliyagil, 2004. Plasma lipid peroxidation and antioxidant levels in patients with rheumatoid arthritis. Cell Biochem. Funct., 22: 53-57. PMID: 14695655

Karatas, F., I. Ozates, H. Canatan, I. Halifeogly and M. Karatepe et al., 2003. Antioxidant status and lipid peroxidation in patients with rheumatoid arthritis. Indian J. Med. Res., 118: 178-181. PMID: 14700353

Koksal, H. and S. Kurban, 2010. Total oxidant status, total antioxidant status and paraoxonase and arylesterase activities during laparoscopic cholecystectomy. Clinics, 65: 285-290.

Martin, R.H., 1998. The role of nutrition and diet in rheumatoid arthritis. Proc. Nutr. Soc., 57: 231-234. PMID: 9656325

Mikuls, T.R., 2003. Co-morbidity in rheumatoid arthritis. Best Pract. Res. Clin. Rheumatol., 17: 729-752. PMID: 12915155

Nourmohammadi, I., S. Athari-Nikazm, M.R. Vafa, A. Bidari and S. Jazayeri et al., 2010. Effects of antioxidant supplementations on oxidative stress in rheumatoid arthritis patients. J. Biol. Sci., 10: 63-66.

Pattison, D.J., A.J. Silman, N.J. Goodson, M. Lunt and D. Bunn et al., 2004a. Vitamin C and the risk of developing inflammatory polyarthritis: Prospective nested case-control study. Ann. Rheum Dis., 63: 843-847. DOI: 10.1136/ard.2003.016097

Pattison, D.J., D.M. Symmons and A. Young, 2004b. Does diet have a role in the aetiology of rheumatoid arthritis? Proc Nutr. Soc., 63: 137-143. PMID: 15099410

Pattison, D.J. and P.G. Winyard, 2008. Dietary antioxidants in inflammatory arthritis: Do they have any role in etiology or therapy? Nat. Clin. Pract. Rheumatol., 4: 590-596. PMID: 18825134

Peng, J., G.L. Jones and K. Watson, 2000. Stress proteins as biomarkers of oxidative stress: effects of antioxidant supplements. Free Radic. Biol. Med., 28: 1598-1606. DOI: 10.1016/S08915849(00)00276-8

Pretez, A., V. Siderova and J. Neve, 2001. Selenium supplementation in rheumatoid arthritis investigated in a double blind, placebo-controlled trial. Scand J. Rheumatol., 30: 208-212. PMID: 11578015 
Rennie, K.L., J. Hughes, R. Lang and S.A. Jebb, 2003. Nutritional management of rheumatoid arthritis: A review of the evidence. J. Hum. Nutr. Diet, 16: 97-109. PMID: 12662368

Rozenberg, O., M. Rozenblot, R. Coleman, D.M. Shih and M. Aviram, 2003. Paraoxonase (PON1) deficiency is associated with increased macrophage oxidative stress: Studies in PON1-knockout mice. Free Radic. Biol. Med., 34: 774-784. PMID: 12633754

Sarban, S., A. Kocyigi, M. Yazar and U.E. Isikan, 2005. Plasma total antioxidant capacity, lipid peroxidation and erythrocyte antioxidant enzyme activities in patients with rheumatoid arthritis and osteoarthritis. Clin. Biochem., 38: 981-986. PMID: 16150434

Shinde, S.A., A.N. Suryakar, A.N. Sontakke and U.K. More, 2010. Effect of antioxidant vitamin supplementation on erythrocyte membrane composition in Type I diabetes mellitus in context of oxidative stress. Biomed. Res., 21: 156-160.

Sorenson, R.C., S.L. Primo-Parmo, C.L. Kuo, S. Adkins and O. Lockridgee et al., 1995. Reconsideration of the catalytic center and mechanism of mammalian paraoxonase/arylesterase. Proc. Natl. Acad. Sci., 92: 7187-7191.

Stamp, L.K., M.J. James and L.G. Cleland, 2005. Diet and rheumatoid arthritis: A review of the literature. Semin Arthritis Room, 35: 77-94. PMID: 16194694

Tarp, U., K. Overvad, E.B. Thorling, H. Graudal and J.C. Hansen, 1985. Selenium treatment in rheumatoid arthritis. Scand J. Rheumatol., 14: 364368. DOI: $10.3109 / 03009748509102039$
Taysi, S., F. Polat, M. Gul, R.A. Sari and E. Bakan, 2002. Lipid peroxidation, some extracellular antioxidants and antioxidant enzymes in serum of patients with rheumatoid arthritis. Rheumatol. Int., 21: 200-204. PMID: 11958437

Venkatraman, J.T. and W.C. Chu, 1999. Effects of dietary omega-3 and omega- 6 lipids and vitamin $\mathrm{E}$ on serum cytokines, lipid mediators and Anti-DNA antibodies in a mouse model for rheumatoid arthritis. J. Am. Coll Nutr., 18: 602-613. PMID: 10613412

Wang, J., Q. Zhang, S. Jin, D. He and S. Zhao et al., 2008. Genistein modulate immune responses in collagen-induced rheumatoid arthritis model. Maturitas, 59: 405-412. DOI: 10.1016/j.maturitas.2008.04.003

Westaway, M.S., P. Rheeder and G. Guloba, 2008. Rheumatoid arthritis functional disability in a public health care clinic. S. Afr. Med. J., 98: 706706. PMID: 19113050

WHO, 2009. Global prevalence of vitamin A deficiency in populations at risk 1995-2005. WHO Global Database on Vitamin A Deficiency. World Health Organization, Geneva.

Yang, W., P. Wang, Y. Jing, Z. Yang and C. Zhang et al., 2010. Effects of vitamin A on growth performance, antioxidant status and blood constituents in lactating grey goat. Am. J. Anim. Vet. Sci., 5: 274-281. DOI: 10.3844/ajavsp.2010.274.281 